Case report

\title{
Reversible renal impairment induced by treatment with the angiotensin II receptor antagonist candesartan in a patient with bilateral renal artery stenosis Thomas Lund Johansen and Andreas Kjær*
}

\author{
Address: Department of Clinical Physiology and Nuclear Medicine, Frederiksberg Hospital, Copenhagen University Hospital, Nordre Fasanvej \\ 57, DK-200o Frederiksberg, Denmark \\ E-mail: Thomas Lund Johansen - tlj@dadlnet.dk; Andreas Kjær* - kjaer@mfi.ku.dk \\ *Corresponding author
}

Published: 17 May 2001

BMC Nephrology 200I, 2:I

This article is available from: http://www.biomedcentral.com//47I-2369/2/I

(c) $200 \mathrm{I}$ Johansen and Kjær, licensee BioMed Central Ltd.
Received: 13 February 200|

Accepted: 17 May 200I

\begin{abstract}
Background: It is well established that ACE-inhibitors should be avoided in patients with renal artery stenosis. In recent years it has also been recommended that caution should be demonstrated when angiotensin II blockers are used in the same type of patients but the evidence is based only on few cases.

Results: We describe a case where use of the angiotensin II antagonist candesartan (Atacand) induced renal failure in a patient with bilateral renal artery stenosis. The course of the case is enlighted by results from sequential renography, selective renal vein catheterisation for measurement of renin, and angiographic findings.
\end{abstract}

Conclusions: In patients with renal artery stenosis the angiotensin II antagonist candesartan should be avoided.

\section{Background}

ACE-inhibitors are well-established in treatment of hypertension. In recent years selective angiotensin II $\mathrm{AT}_{1^{-}}$ receptor antagonists have been introduced as an alternative. Although the same system is manipulated, the two types of medication differ in several ways. In brief, the major differences are: 1) whereas blockade of angiotensin II formation by ACE-inhibition is incomplete due to alternative synthesis pathways, e.g. chymase pathway, angiotensin II antagonists block the receptors at the target organ, 2) the relative effect on $\mathrm{AT}_{1^{-}}$and $\mathrm{AT}_{2}-$ receptors, and 3) differential effect on bradykinin metabolism since ACE inhibition inhibits ACE inactivation of bradykinin. The latter is thought to be the major reason for the higher rate of side-effects seen with ACE inhibitors compared to angiotensin II antagonists. Whereas the evidence that ACE-inhibitors should be avoided in patients with renal artery stenosis is substantial, the evi- dence is more sparse with regard to angiotensin II antagonists and restricted to losartan.

Below, we present a case of reversible deterioration in renal function following treatment with the angiotensin II antagonist candesartan.

\section{Case}

A 60 years old male with previous alcohol abuse and known hypertension for the last 5 years was admitted to our hospital with a diagnosis of hypertension. At the time of admission the blood pressure (BP) was 230/140 $\mathrm{mmHg}$ despite treatment with metoprolol (Selozok), amiloride/hydrochlorthiazide (Sparkal Mite) and candesartan (Atacand). The patient was hyperkalemic and had an increased serum-creatinine $(237 \mu \mathrm{mol} / \mathrm{l})$. Antihypertensive treatment was intensified including addition of loop-diuretic and hydration. 


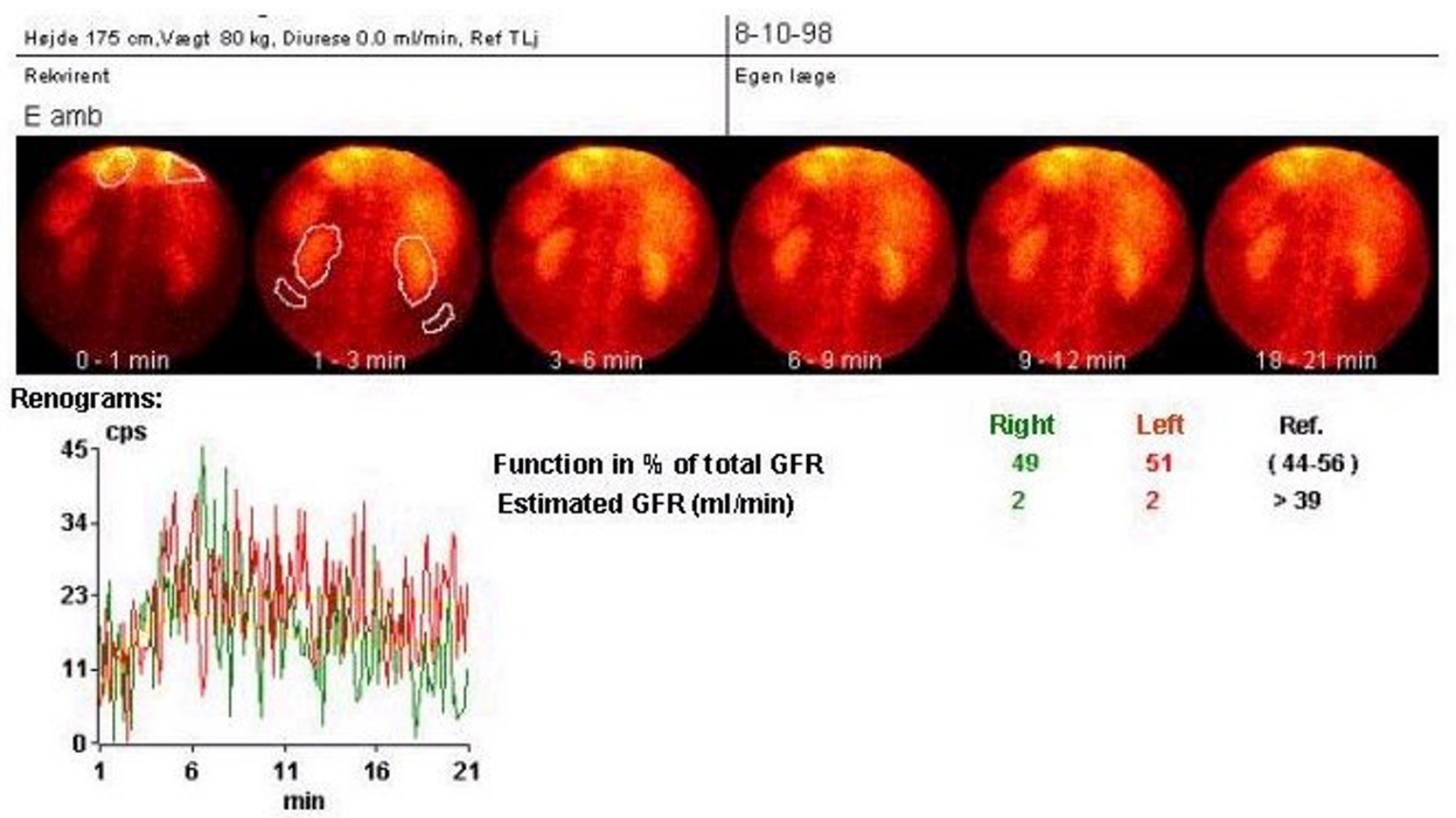

Figure I

Renography during candesartan treatment.

Following normalization of BP, serum-potassium and serum-creatinine the patient was discharged with an appointment for ambulatory renography. ${ }^{99 \mathrm{~m}} \mathrm{Tc}$-DTPA renography (Fig. 1), performed after the patient had been on candesartan treatment for 4 months, showed symmetrical renal function, however, the absolute renal function was almost abolished (total estimated GFR 4 $\mathrm{ml} / \mathrm{min})$.

At the time the patient had an elevated serum-creatinine $(817 \mu \mathrm{mol} / \mathrm{l})$ and urea $(48 \mathrm{mmol} / \mathrm{l})$ and was anuric. Diuresis was re-established following use of intravenous loop-diuretic and hydration. Renal biochemistry then improved. Atacand was discontinued and 3 weeks later renography (Fig. 2) demonstrated improved renal function: total estimated GFR $47 \mathrm{ml} / \mathrm{min}$. The left kidney was responsible for only $1 / 3$ of the total renal function.

Later, a selective catheterisation of the renal veins was performed for measurement of renin. The renin measurements showed increased left sided renin production (Table 1). Arteriography showed an arteriosclerotic abdominal aorta with significant bilateral stenosis of the renal arteries, more prominent on the left side.
The patient was referred to PTA of the left renal artery stenosis. Under the procedure for PTA, which was unsuccessful bilateral renal occlusion occurred. The patient then underwent bilateral vein graft renal arterial bypasses.

Two months after this operation renography showed improved absolute and relative function of the left kidney whereas the absolute function of the right kidney was unchanged (Fig. 3). Furthermore, pre- and post-captopril renography appearances were similar (Figs. 3-4), indicating no functionally important stenosis. A 24-hour ambulatory BP measurement showed well-regulated BP under treatment with amlodipine (Norvasc), doxazosin (Carduran) and bendroflumethiazide (Centyl).

\section{Discussion}

It is well established that ACE inhibitors should be avoided in patients with critical renal artery stenosis. In contrast, this is not as well established with respect to angiotensin II antagonists. Over the last years a few cases have shown that renal function may be impaired if the angiotensin II antagonist losartan is used in patients with renal artery stenosis $[1,2,3,4]$ but two of these cases were in the special situation of kidney transplants $[3,4]$. To our knowledge we are the first to report a case of renal 


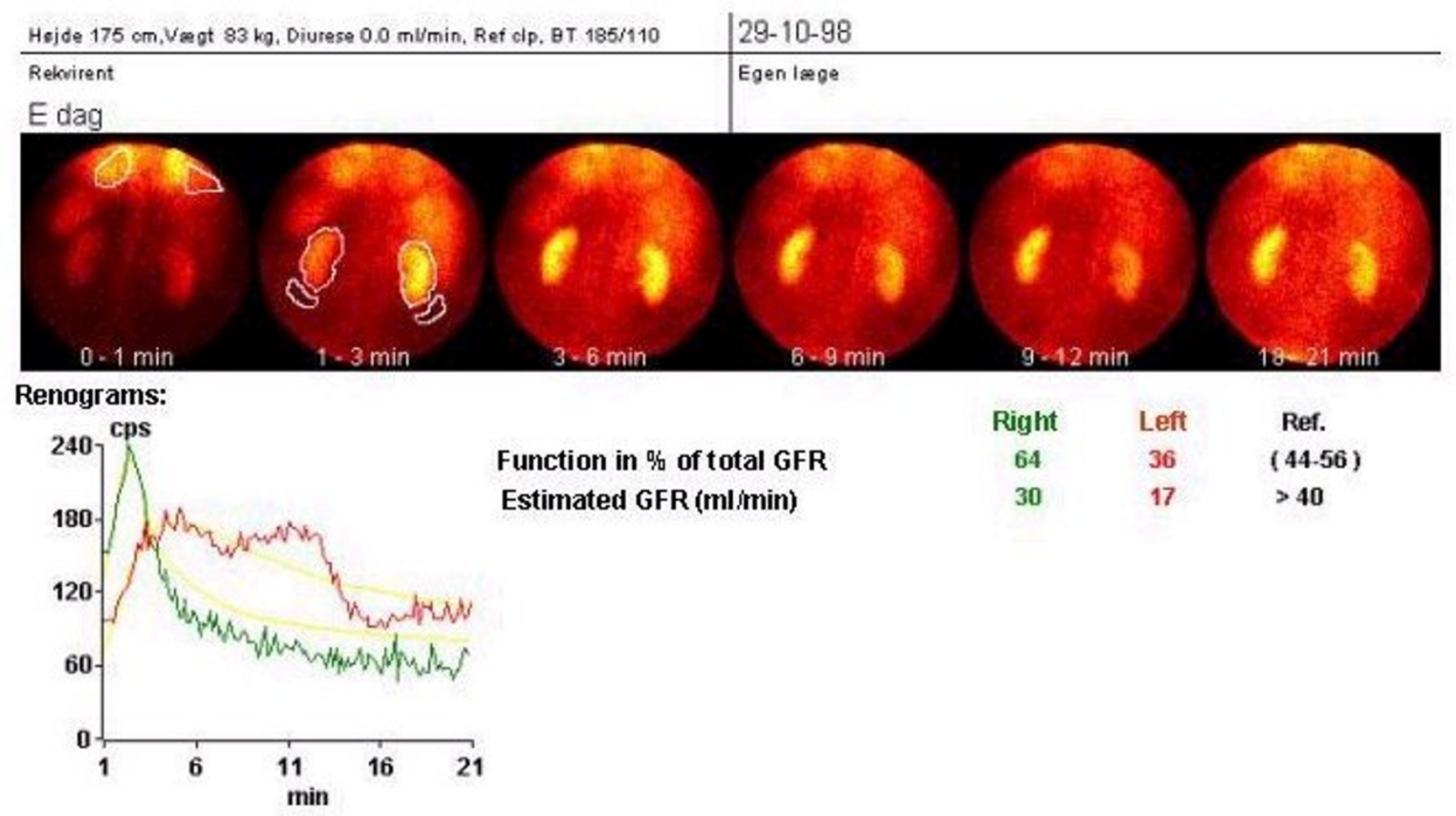

Figure 2

Renography 3 weeks after discontinuation of candesartan treatment.

impairment induced by the angiotensin II antagonist candesartan. Subsequent to the introduction of losartan, several other angiotensin II blockers have been marketed over the last couple of years and differences in receptor affinity and kinetics are reported. Therefore, our case supports the thought that caution should be shown using other types of angiotensin II antagonists. As mentioned in the introduction several differences exist between ACE inhibitors and angiotensin II, $\mathrm{AT}_{1}$-receptor antagonists. Therefore, differences with regard to interference with renal function and thereby when the compound should be avoided could exist. From a theoretical point of view however, one would expect that both principles of blockade should be avoided in renal artery stenosis. The mechanism of the renin-angiotensin system in regulation of renal function is believed primarily to be due to the effect of angiotensin II on the efferent arteriolar tone keeping the pressure relatively constant in the glomerulus and thereby keeping GFR constant over a wide range of perfusion pressures, i.e. systemic BP. However, the differential effect on e.g. bradykinin, which is a vasodilator and also have other actions, could in theory make the two types of blockade clinically different. At present, the relative risk of precipitating renal failure by using the different compounds is unsettled. Thus in one case renal function deteriorated following both the ACE inhibitor enalapril and losartan [1]. In contrast, another case-report observed deterioration of renal function during enalapril treatment but no effect of subsequent losartan treatment [5]. Conversely, in a study comparing the usefulness of the ACE inhibitor captopril and losartan renography for detection of renovascular hypertension it was in a single case found that losartan but not captopril induced a fall in renal function in a kidney with more than $80 \%$ renal artery stenosis [6].

Our case also demonstrates that renography is an easy way to examine and follow patients with deterioration of renal function during treatment with angiotensin II antagonists or ACE inhibitors. When of relevance, the additional use of angiography and selective renin measurements add further evidence for the reason for renal impairment.

We conclude, that further studies are needed to demonstrate potential differences in the use of ACE inhibitors and angiotensin II antagonists in patients with suspected renal artery stenosis. Until then, both compounds should be avoided in this category of patients. 
Højde $171 \mathrm{~cm}$, Væagt $86 \mathrm{~kg}$, Diurese $5.7 \mathrm{mumin}$, Ref JM, BT 165i16-7-99

\begin{tabular}{l|l}
\hline Rekvirent & Egen læge \\
$\mathrm{EL}$ & \\
\hline
\end{tabular}

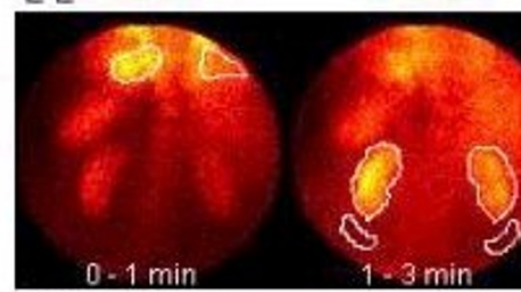

Renograms:

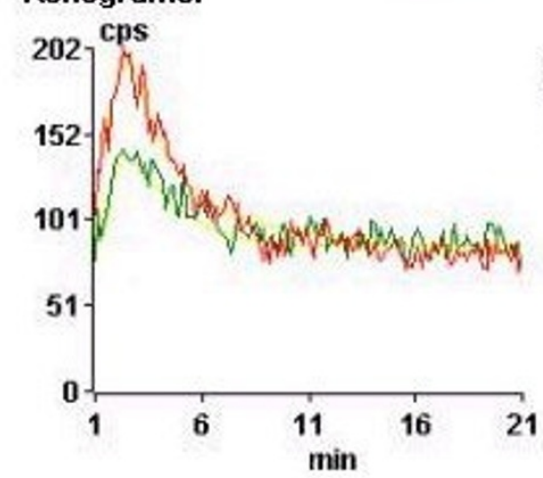

Function in $\%$ of total GFR

Estimated GFR (mlimin)
$6=9 \min$

3. $6 \mathrm{~min}$

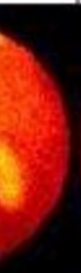

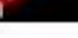

$9=12 \mathrm{~min}$

Right

42

21

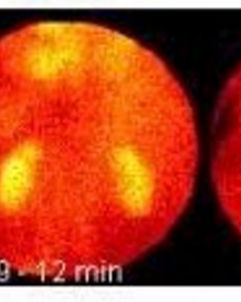

18
8.21 min

Ref. (44.56) $>39$

Figure 3

Renography following bilateral renal by-pass surgery.

Table I: Levels of renin in the renal veins demonstrating increased levels on the left side. Values are in $\mathrm{mIU} / \mathrm{I}$.

\begin{tabular}{lccc}
\hline & Right renal vein & Left renal vein & Reference (antecubital vein) \\
\hline $\begin{array}{l}\text { Without loop-diuretic } \\
\text { stimulation }\end{array}$ & 92 & 148 & 92 \\
$\begin{array}{l}\text { With loop-diuretic } \\
\text { stimulation }\end{array}$ & 105 & 230 & 103 \\
\hline
\end{tabular}




\section{Højde $171 \mathrm{~cm}$, Væegt $86 \mathrm{~kg}$, Diurese $7.7 \mathrm{mumin}$, Ref JM, BT 148id 9-7-99}

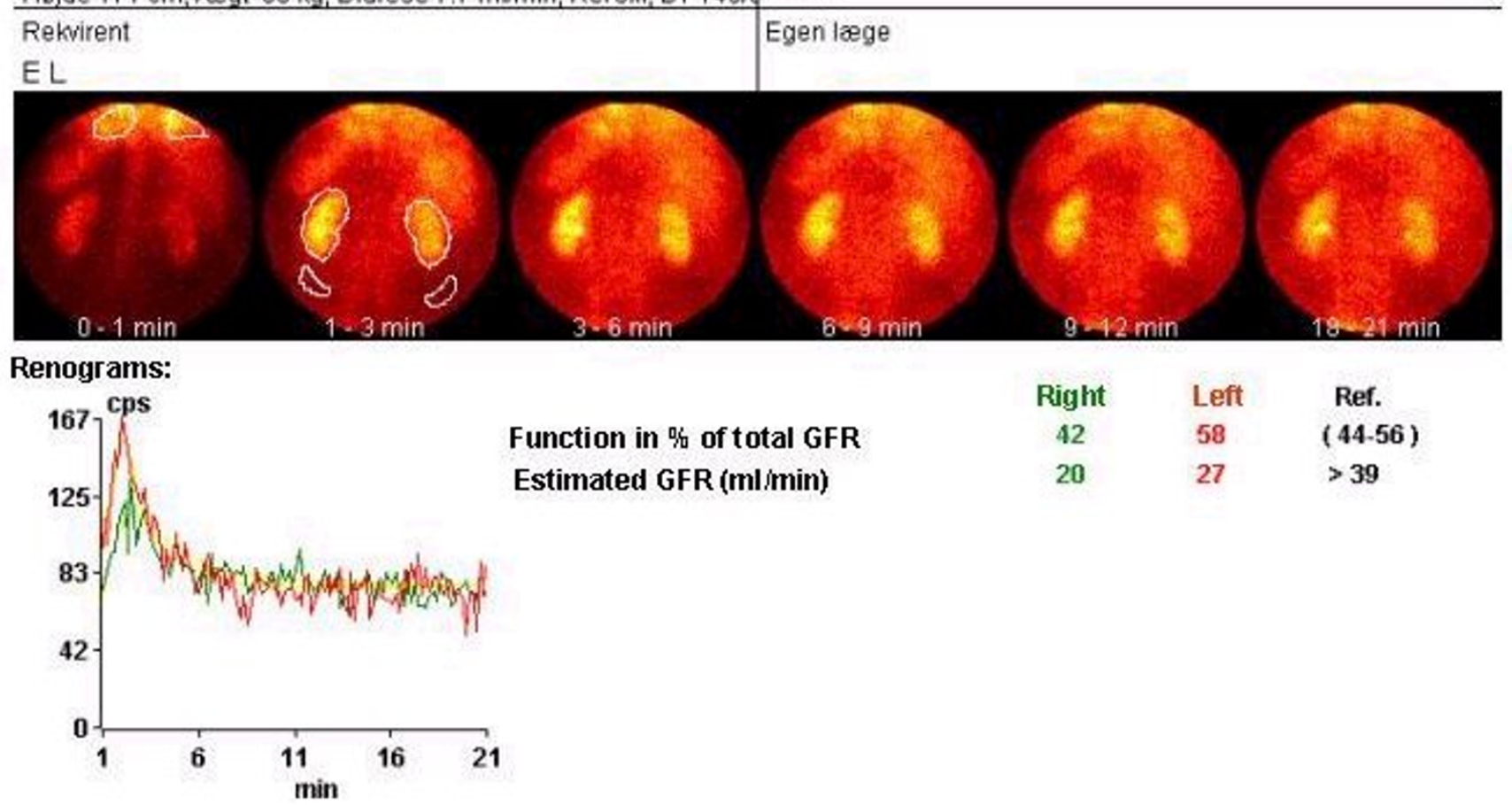

Figure 4

Captopril renography following bilateral renal by-pass surgery.

\section{Note}

Written consent for publication of the case was obtained from the patient.

\section{Competing interests}

None declared

\section{References}

I. Cohen LS, Friedman EA: Losartan-induced azotemia in a diabetic recipient of a kidney transplant. N Engl J Med 1996, 334: I27I1272

2. Holm EA, Randlov A, Strandgaard S: Brief report: acute renal failure after losartan treatment in a patient with bilateral renal artery stenosis. Blood Press 1996, 5:360-362

3. Ostermann M, Goldsmith DJ, Doyle T, Kingswood JC, Sharpstone P: Reversible acute renal failure induced by losartan in a renal transplant recipient. Postgrad Med J 1997, 73:105-107

4. Saine DR, Ahrens ER: Renal impairment associated with losartan. Ann Intern Med 1996, I 24:775

5. Missouris CG, Ward DE, Eastwood JB, MacGregor GA: Deterioration in renal function with enalapril but not losartan in a patient with renal artery stenosis in a solitary kidney. Heart 1997, 77:391-392

6. Fuster D, Paz MM, Setoain FJ, Oppenheimer F, Lomena F: A case of renal artery stenosis after transplantation: can losartan be more accurate than captopril renography? Clin Nucl Med 1998, 23:731-734

\section{Pre-publication history}

The pre-publication history for this paper can be accessed here:

http://www.biomedcentral.com/content/backmatter/ 1471-2369-2-1-b1.pdf
Publish with BioMedcentral and every scientist can read your work free of charge

"BioMedcentral will be the most significant development for disseminating the results of biomedical research in our lifetime." Paul Nurse, Director-General, Imperial Cancer Research Fund

Publish with BMc and your research papers will be:

- available free of charge to the entire biomedical community

- peer reviewed and published immediately upon acceptance

- cited in PubMed and archived on PubMed Central

- yours - you keep the copyright

Submit your manuscript here: http://www.biomedcentral.com/manuscript

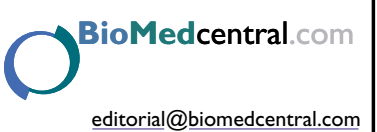

